\title{
Feeding cities: Charting a research and practice agenda toward food security
}

\author{
Catherine Brinkley, ${ }^{\mathrm{a}, \mathrm{b}, \mathrm{c}} *$ Eugenie Birch, ${ }^{\mathrm{a}, \mathrm{b}}$ and Alexander Keating ${ }^{\mathrm{a}}$ \\ University of Pennsylvania
}

\author{
Submitted June 3, 2013 / Revised July 28, 2013 / Published online August 5, 2013 \\ Citation: Brinkley, C., Birch, E., \& Keating, A. (2013). Feeding cities: Charting a research and practice agenda \\ toward food security. Journal of Agriculture, Food Systems, and Community Development, 3(4), 81-87. \\ http://dx.doi.org/10.5304/jafscd.2013.034.008
}

Copyright (C) 2013 by New Leaf Associates, Inc.

\begin{abstract}
This commentary details an action agenda for practice and research contributed to by more than 70 experts and 450 attendees of the Feeding Cities: Food Security in a Rapidly Urbanizing World conference, held at the University of Pennsylvania in March 2013. They discussed such global issues as hunger, malnourishment, and obesity and called for policies to address them through a variety of food production, distribution, and marketing initiatives. They produced a six-point action-based

\footnotetext{
${ }^{\text {a }}$ University of Pennsylvania, Penn Institute for Urban Research

b University of Pennsylvania, Department of City and Regional Planning

c University of Pennsylvania, School of Veterinary Medicine

* Corresponding author: Catherine Brinkley, 102 Meyerson Hall, University of Pennsylvania, 210 South 34th Street, Philadelphia, Pennsylvania 19104; catb@vet.upenn.edu
}

agenda for future food security planning and identified best practice policies for each agenda item. Their objective is to offer a roadmap to produce and supply the world's growing urban population with healthy, affordable, and safe food in a sustainable manner and to avoid potential food security crises across the world.

\section{Keywords}

food access, food distribution, food production, waste

\section{Introduction}

Food security, a commonly used but often misunderstood phrase, entails the production, availability, accessibility, safety, and nutritional value of what we consume. Evidence that food security is a global problem is present in current statistics about hunger, malnourishment, and obesity. Every night nearly 870 million people worldwide go to bed hungry, and at the same time, a billion people are 
suffering from obesity-related diseases that the World Health Organization estimates will be the leading killer of poor people globally by 2030 . Food-related diseases now cause close to 60 percent of all deaths worldwide, with nearly 80 percent of these deaths occurring in developing countries (Food and Agriculture Organization, 2012).

Food-related health outcomes are polarized, and extreme outcomes, such as starvation and obesity, often occur in the same neighborhoods, causing inappropriate conflation of variable causes. Health crises are exhibited in pockets of deprivation where access to healthy foods is often limited and, more broadly, where obesity is epidemic. Because policy, research, and practice addressing both over- and undernutrition must operate in the same locations, they are often contradictory, suggesting more access to calorie-dense foods in areas where there is also obesity, or suggesting limited diets in areas that also experience starvation. Moreover, in dealing with urban food security we are not only contemplating how to feed people, but also addressing attendant social and economic issues. Given the rapid pace and trajectory of today's urbanization, we must act quickly.

\section{Conference Format and Participants}

In March 2013, the Penn Institute for Urban Research, in partnership with the University of Pennsylvania School of Veterinary Medicine and a faculty steering committee representing nine schools and six centers at the University of Pennsylvania, convened the Feeding Cities: Food Security in a Rapidly Urbanizing World conference. Over three days, more than 70 experts from around the world shared multidisciplinary perspectives on the nexus of food security and urbanization with 450 conference attendees representing public, private, and academic institutions and organizations from the U.S. and abroad. The Feeding Cities conference featured three keynote addresses, six plenary sessions, and 12 focused breakout sessions addressing a variety of critical components within overarching food security domains (figure 1).

The conference charted a food security agenda that will build multidisciplinary bridges for emerg- ing best practices in food production and policy with the goal of shaping streams of research, education, and practice by forging new avenues for collaboration among traditionally siloed areas of practice and scholarship. The Feeding Cities conference sessions prioritized dialogue and interaction among panelists and participants. They joined international and local experts, often having opposing viewpoints to foster cross-disciplinary dialogue in finding the middle ground on contentious issues. To view videotaped conference sessions and media coverage, go to the Feeding Cities website. ${ }^{1}$ The conference closed with a participatory working session to suggest the priority areas for research and action necessary to support a more food-secure and nutritionally healthy future for all. This research commentary summarizes the conference findings related to charting a food security agenda.

\section{Areas of Contention, Conflation and Middle Ground}

Feeding Cities speakers and participants identified the need for a coordinated response to the global challenge of food security as a central theme of any future action. In particular, they emphasized the importance of constructing new frameworks in policy and practice to integrate key disciplines and actors. Discussions addressed the following considerations:

\section{Recognize Ancillary Effects of Food Security}

Attendees urged researchers and practitioners to be sensitive to the many strands of influence that the food system exerts on other systems, be they environmental land uses or socioeconomic effects. As Molly Jahn, professor of agronomy and genetics at the Nelson Institute for Environmental Studies, asserted, "I can't demand food without setting up a series of collateral interactions in water, or energy, or greenhouse gas emissions." Heather Grady, vice president of foundation initiatives at the Rockefeller Foundation, echoed this belief: "Food security is about more than keeping hunger at bay, it is about stable societies, productive societies, and

\footnotetext{
${ }^{1}$ http://www.feedingcities.com
} 


\section{Figure 1. Domains of Food Security}

1. Food Production: The science of producing safe and adequate food in the appropriate place considering current and projected urban and agricultural land-use pressures on the environment;

2. Food Distribution: The policies and logistics underlying global and local food distribution systems; and

3. Food Delivery: Emerging trends in diets and nutritional demands across the globe with a focus on placebased food access.

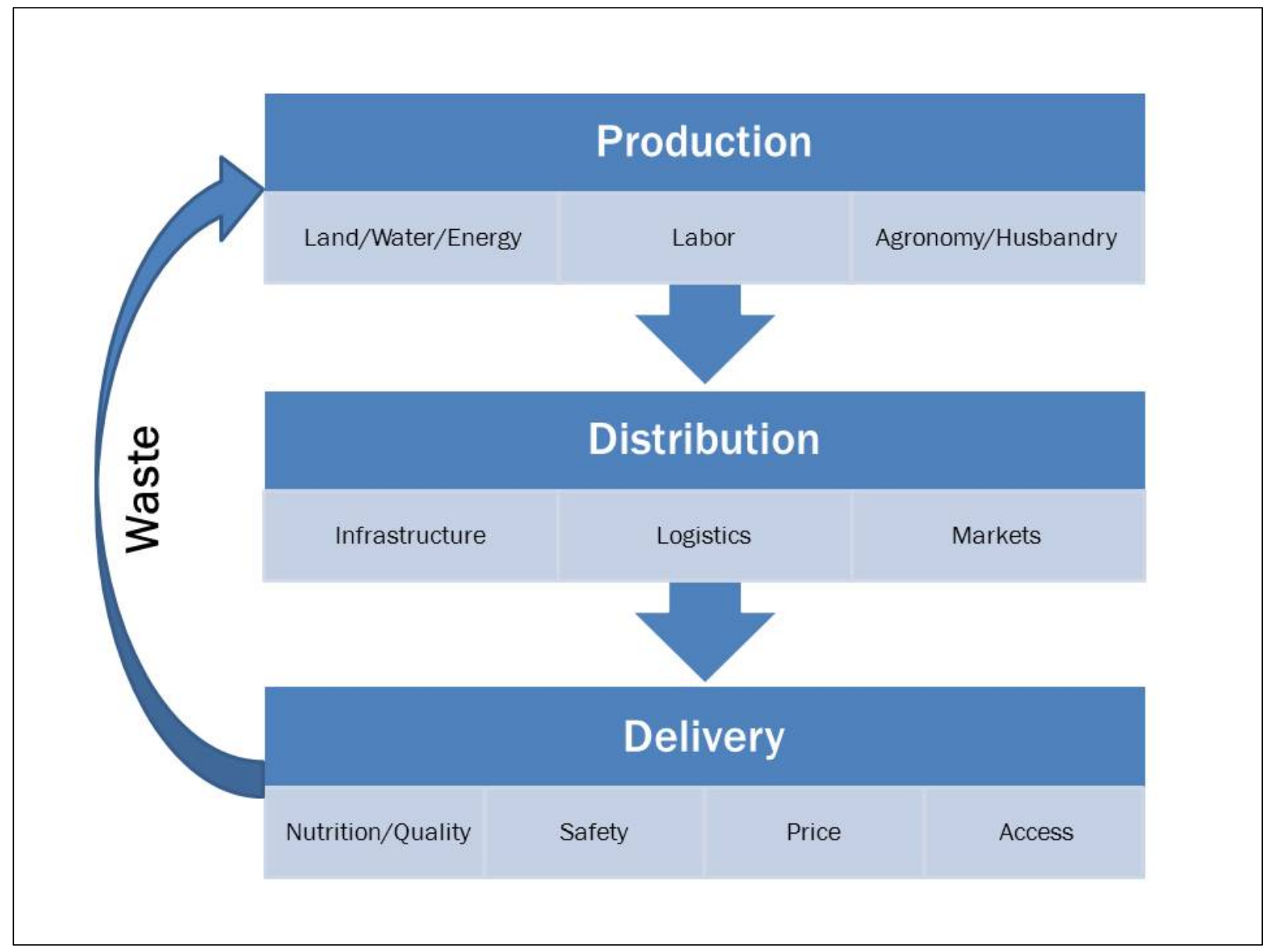

in our twenty-first-century world. We believe it is about resilient societies."

In the U.S. context, Malik Yakini introduced the Detroit Black Community Food Security Network's (DBCSN) concept of food justice as the primary component of a food security movement. Describing the ways in which issues of race, class, and gender have created severe inequalities in global food systems, Yakini called particular attention to the need to re-evaluate the role of food systems for traditionally marginalized groups. Audience members and panelists discussed ways to identify and mitigate the impact of racism in the politics of food systems. This included a call for urban agriculture organizations to analyze their own power dynamics so they can better partner with and empower the communities they are working in and, in essence, devise a strategy to "work themselves out of a job."

Acknowledging that various other systems interact with the food system, numerous panel members called for a reassessment of the nonfood security benefits related to food security domains. They cited, for example, studies on the influence of urban agriculture on surrounding property values, mental health, urban heat island effect, and water filtration. Finally, many observed that in continuing to assess the spin-off benefits or 
drawbacks of food security policies, researchers and practitioners will need to update their metrics and impact assessments to reflect ancillary policy products.

\section{Correct for Contradictory Policies}

Panelists identified multiple competing agendas in food security policy. Some policies unintentionally create competition in various food security scales (figure 2). For example, financial and health regulations that favor large-scale agriculture which can more readily comply with packaging and safety laws, allow the global feedback loop to flourish at the expense of more local and regional feedback loops. Some policies may be contradictory but research is lacking to either prove or disprove such conditions. For example we need longitudinal studies to examine the impact of emergency food distribution to see if this moves people towards food self-sufficiency or dependency. More obvious are the policies that are in direct contradiction, such as the existing divide between anti-hunger advocates (mainly addressing undernutrition and the lack of access to necessary calories) and public health advocates (mainly addressing overnutrition in the sense of obesity and diet related disease). Participants outlined the need for a model through which both of these issues could be simultaneously addressed in development and food-security agendas in a way that is compatible rather than in competition. Recommendations included shifting emphasis towards the provisioning of fresh fruits and vegetables as a cornerstone of local food policy and emergency feeding programs, and away from

Figure 2. Feedback Loops in Various Scales of Food Supplies and Markets To Sustain Urban Food Supply and Rural Economy

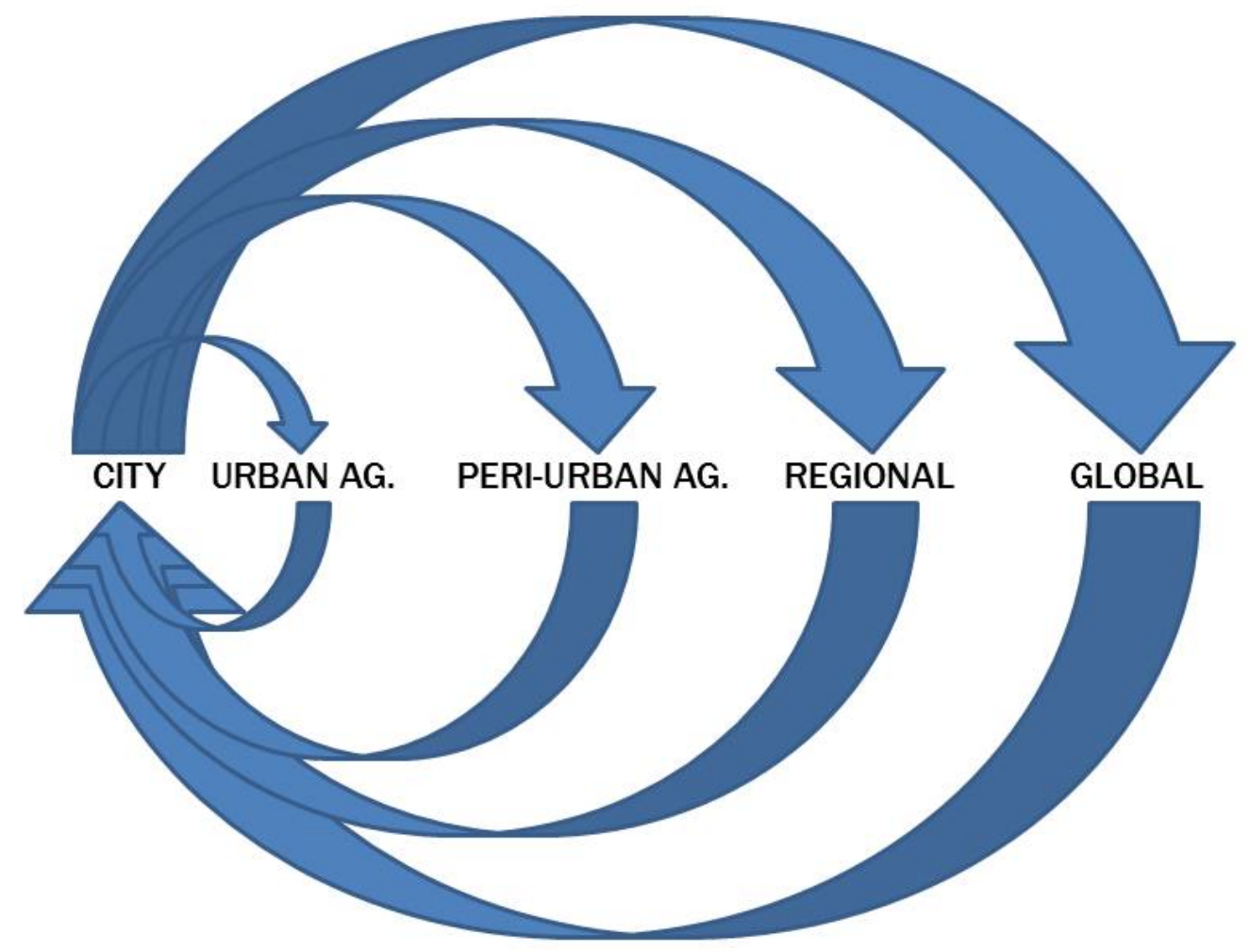


cheaper, more calorie-dense processed foods. Contradictions also exist in economic planning policies. For example, increasing food production often calls for increasing the price of food to incentivize farmers, while efforts to reduce current hunger and malnutrition in cities must work to reduce the price of food. This necessary balance of investment in food availability (production) and access (distribution) was echoed in discussion of the importance of global trade in providing urban populations with staple foods at low prices, while domestic agricultural policies must simultaneously support the profitability and viability of local food production and rural livelihoods. To address this, governments will need to play a central role in correcting locally for price distortions on the global market. In Belo Horizonte, Brazil, for example, the public sector buys food from local farmers, supporting peri-urban agriculture while making fresh food available at a discount to all citizens, a program that destigmatizes public food access or relief. Leveraging key partnerships with the federal government, the municipality of Belo Horizonte is able to run this comprehensive package of policies and programs with on only 2 percent of the city's budget (Rocha, 2001). As a result of Belo Horizonte's success, Brazil has encouraged the adoption of local Food Councils throughout the country.

\section{Need for Multiple Systems and Scales}

\section{in Resiliency Planning}

In meeting the demand for increased food production necessary to keep pace with projected increases in urban populations, conference participants underlined the need for comprehensive food policy initiatives that integrate centralized animal production and agricultural practices, smallholder farming, and urban and peri-urban agriculture in order to create a resilient food system, rather than one that places these practices in competition with one another in efforts to provision cities. Just as urban agriculture cannot replace rural agriculture in terms of the necessary agricultural yields and products, regional and global food production systems are unlikely to provide responsive, secure, and affordable sources of fresh fruits and vegetables to vulnerable urban populations in times of environmental stress and price shocks. A resilient food system, in this case, is composed of spare capacity, redundancy, and adaptability at multiple scales, utilizing a variety of production techniques and sites, and characterized by functioning feedback loops throughout (figure 2).

\section{Step 1: Plan}

Joan Clos, former mayor of Barcelona and current executive director of the United Nations Human Settlements Program (UN-Habitat), brought a broader perspective to the global challenges of proactively planning for urban growth. Clos emphasized the importance of planning in charting a path toward sustainable food systems. He punctuated that point by noting that attendees were walking down the same grid of streets in Philadelphia that William Penn laid out 400 years ago. "If we don't plan today, we are already too late."

Comprehensive planning can coordinate goals and research already established for many domains of food security (figure 1), such as improving yields through food science. For food production, Penn professor Thomas Daniels noted that, "it is very important to have a comprehensive plan that cites agriculture as an important industry that you want to maintain well into the future. This will set the legal basis for your zoning." Similarly, in urban environments, panelists noted a need for supportive land use policies to allow city farming. "Land access, including the quality of the land and especially land tenure, largely defines urban agriculture's ability to impact community food security," asserted University of Pennsylvania professor Domenic Vitiello. While much needs to be done to coordinate urban growth and farmland retention, panelists urge land use planners to retain elements of flexibility in prescribed land use patterns. Kevin Morgan, coauthor of The School Food Revolution, noted at the conference that "the key point is multifunctionality...It is incumbent on the food movement to be a big tent, to frame food policy in a sufficiently capacious way." Regional systems of distribution and waste recycling may require the planning of specific infrastructure improvements to support multifunctional areas of food production, recreation, and wildlife habitat. All of this planning must be coordinated; plans that match food security needs with food access points can 
guide more efficient delivery systems. Lastly, as with the success of food security planning in Belo Horizonte, panelists emphasized the need for pilot projects to try new policies, evaluate success, and then scale up.

As a subheading to the planning step, the following areas were identified as important action agendas. These agendas are to be considered together rather than being considered stand-alone solutions. As panelist Molly Jahn noted, "maximizing short-term crop production doesn't equate to food security and certainly not nutritional security or nutritional health"; all policies must occur in tandem.

Point 1. Production: As wasteful food delivery practices hinge on having such an abundance of cheap food that the cost of efficiency outweighs the cost of waste, policies to raise more food must be connected with policies to reduce food waste, targeting both ends of a connected system. To this end, Carl Hausmann, global policy advisor at Bunge Limited, and Raj Khosla, professor of precision agriculture at Colorado State University, both recommended sustainable small-plot production intensification with precision agriculture as a policy that could improve crop yield and provide crop diversity without wasting resources through over-applying water or fertilizer.

Point 2. Distribution: Bill Clark, the executive director of Philabundance, a food relief organization, noted, "at root, we believe that the ideal food distribution for poor people looks exactly like the ideal distribution system for rich people, it just has a different price structure." To this end, the role of the informal sector has been overlooked as an ally in supplying healthy food. Panelists agreed that significant data failures exist in describing trade and investment due to the informal sector, and that improved mechanisms for capturing and integrating this information are necessary. Researchers and practitioners need to build relationships with informal food practitioners to better understand supply structures, food safety, and the potential to plan for or support informal food economies.
Point 3. Delivery and Access: Participants stressed the importance of integrating measurements of nutritional health and nutrient content in assessing food security. While the production and availability of food remains critical to global food security, conference participants were clear that "not all calories are equal" and that understanding the link between food production policies and systems and the delivery of micro- and macronutrients to food-insecure populations is critical to comprehensive food systems planning. To this end, healthy food such as fresh produce should be priced lower than unhealthy food to ensure access by food-stressed populations without creating bifurcations in health.

Point 4. Waste Feedback Loop: There is a need for new urban planning paradigms to acknowledge the importance of proximity between urban centers and agriculture and to supplement the existing, linear model of international production and distribution with a more cyclical, closed-loop relationship between urban areas and their immediate food-producing hinterlands. Dr. Van der Steen described emerging practices in urban water re-use aimed not only at preserving water, but also allowing for the separation, treatment, and recapture of nutrients from human waste at the household and urban level, proposing new, sustainable integration of urban waste recycling and agricultural production. The infrastructure reorientation and development to support feedback loops must be supported by municipal codes and public health codes.

\section{Point 5. Build Knowledge Networks: Broadly} speaking, the call for improved knowledge networks suggests a two-way flow of information to replace one that has hitherto been mainly unidirectional in terms of educational outreach for nutrition or agricultural extension programs. Numerous conference participants noted the benefits of social engagement and communitybuilding in cities centered around agriculture or food, and the importance of social media in building these networks. Agricultural cooperatives, farmers' markets, and local food or entertainment procurement can all be organized through virtual portals that help right-size the event or service 
delivery. To this end, researchers and practitioners should analyze the appropriate technology and context for engaging the community in building knowledge hubs to spread innovation.

\section{Point 6. Economic Drivers of Food: Jim} Harkness, director of the Institute for Agriculture and Trade Policy, noted how far-reaching, highimpact land use decisions are being guided by the highly centralized and globally funded food industry. The response to high or unstable food prices has prompted the private sector to engage in large-scale purchases of agricultural land in the global south. These "land grabs" have been fueled by food import-dependent countries attempting to outsource their food production and supply and by the uncertainty in global financial market where "hundreds of billions of dollars were sloshing around after the global financial crisis looking for a place to land." Less coordinated but still influential are the effects of urbanization and associated income increases, which result in dietary demand shifts toward protein and nutrient-rich foods. The shifts in demand, while good for those whose incomes are rising and the farmers producing the goods, are having a severe impacts on those whose incomes are not growing, presenting major issues of equality and access within cities. Research is needed to identify practices and policies to correct for damaging financial influence on the global food system. Within this debate, the potential of utilizing antitrust law to curb the consolidation of agriculture was raised as a tool to encourage proliferation of more local feedback loops, which would be more readily responsive to citizen demands for product and ancillary benefits or drawbacks to specific agricultural practices.

\section{Conclusion}

In conclusion, the future efforts for a food security agenda will entail cross-coordinating efforts within each of the food security domains to ensure compatibility. This work will require public decisionmakers to call on key experts in traditionally siloed fields of study: agricultural and veterinary scientists, public health professionals, city and regional planners, and business leaders will need to crossreference policies to find efficient ways to make more healthy food available where population and obesity-related diseases are growing. This means increasing crop and livestock productivity and ecologically sustainable, particularly where agriculture and human populations are close. Already there are complementary best practices identified across all food security domains: promoting precision agriculture production on protected farmland near cities to be distributed to foodstressed populations suffering from both hunger and obesity with food-waste composting and recycling back to nearby farmland. Execution of such programs is complicated but not insurmountable.

\section{References}

Food and Agriculture Organization of the United Nations [FAO]. (2012). The state of food insecurity in the world 2012. Rome: FAO, the International Fund for Agricultural Development, and the World Food Programme. Available from http://www.fao.org/publications/sofi/en/

Rocha, C. (2001). Urban food security policy: The case of Belo Horizonte, Brazil. Journal for the Study of Food and Society, 5(1), 36-47. http://dx.doi.org/10.2752/152897901786732735 